\title{
Radiosurgery for Pituitary Metastases
}

\author{
Yoshiyasu IWAI, Kazuhiro YAMANAKA, Yuji HONDA, and Yasuhiro MATSUSAKA \\ Department of Neurosurgery, Osaka City General Hospital, Osaka
}

\begin{abstract}
Gamma knife radiosurgery (GKS) was used to treat seven patients with pituitary metastases between November 1994 and February 2003. The diagnoses were based on magnetic resonance imaging and clinical symptoms in six patients and by previous surgery in one patient. The cancer originated in the lung in five patients, and in the breast in two patients. The tumor volume was 0.2 to $9.6 \mathrm{~cm}^{3}$ (mean $4.0 \mathrm{~cm}^{3}$ ). The marginal dose was 10 to $14 \mathrm{~Gy}$ (mean $11.9 \mathrm{~Gy}$ ) because of the close proximity to the optic apparatus. The maximum radiation dose to the optic apparatus was 8 to $10 \mathrm{~Gy}$ (mean 9.5 Gy). The survival period after GKS was 0.3 to 42 months (mean 11.5 months). Five patients died of systemic disease, and one patient died of unknown causes 10 days after GKS. Tumor growth was controlled in five of the six patients (83\%) followed up after GKS. Tumor regrowth was seen 18 months after GKS in one patient. The clinical symptoms improved in five of the six patients (83\%) followed up. GKS is effective and useful for the primary treatment of pituitary metastases with limited survival and less invasiveness compared to conventional radiation therapy.
\end{abstract}

Key words: pituitary gland, metastasis, radiosurgery, gamma knife

\section{Introduction}

Pituitary metastases are found in $1.0 \%$ to $26.7 \%$ of cancer patients at autopsy, but very rarely manifest clinically. ${ }^{15,22)}$ The most common source for metastases to the pituitary glands is breast cancer (49.8\%), followed by cancers of the lung $(20.2 \%)$, the gastrointestinal tract $(6.4 \%)$, the prostate gland $(6.0 \%)$, and the pancreas $\left.(4.2 \%){ }^{19}\right)$

The treatment for these lesions usually involves surgery and/or a combination of local or whole brain radiation therapy. ${ }^{20)}$ Modern neuroimaging modalities allow the diagnosis of such metastases with a high degree of accuracy. ${ }^{23)}$ Recently the efficacy of radiosurgery for brain metastases has been established based on the lower radiation exposure to adjacent tissues compared to conventional radiation therapy. ${ }^{25)}$ Nonetheless, only one patient with pituitary metastasis has been treated via radiosurgery. ${ }^{8)}$ Radiosurgery may be limited in use because of the proximity of the optic apparatus to the pituitary gland. ${ }^{16)}$

Here we describe the treatment of seven patients with pituitary metastases using gamma knife radiosurgery (GKS) and discuss the efficacy of this treatment strategy for pituitary metastases.

Received July 22, 2003; Accepted October 15, 2003

\section{Patients and Methods}

Seven patients with pituitary metastases, two men and five women aged 47 to 78 years (mean 64 years), were treated between November 1994 and February 2003 by GKS. The clinical characteristics of the patients are shown in Table 1. The extracranial lesions were controlled in four patients and not controlled in three patients. Four patients had pituitary dysfunction, anterior pituitary dysfunction in two and diabetes insipidus in two. Three patients suffered diplopia due to ocular nerve dysfunction. One patient had no symptoms related to pituitary metastases and the diagnosis was related to other intracranial lesions. The pituitary metastases were associated with other intracranial metastases in four patients. Prior to radiosurgery, one patient underwent surgery in another institute and was referred for regrowth of the tumor. The other patients were treated under diagnoses based on clinical and radiological findings. One patient had received whole brain radiation therapy for multiple metastases.

Radiosurgery was performed using a gamma knife unit (Elekta Instruments AB, Stockholm, Sweden). Stereotactic magnetic resonance (MR) imaging was obtained for dose planning in all patients. The dose planning was performed using the GammaPlan (Elekta Instruments $\mathrm{AB}$ ). The mean tumor diameter varied from 7.2 to $26.4 \mathrm{~mm}$ (mean $16.9 \mathrm{~mm}$ ). The 
Table 1 Clinical characteristics of pituitary metastases in seven patients treated by gamma knife radiosurgery (GKS)

\begin{tabular}{|c|c|c|c|c|c|c|c|}
\hline $\begin{array}{l}\text { Case } \\
\text { No. }\end{array}$ & $\begin{array}{l}\text { Age } \\
\text { (yrs)/ } \\
\text { Sex }\end{array}$ & $\begin{array}{l}\text { Origin of } \\
\text { cancer }\end{array}$ & Histology & $\begin{array}{l}\text { Clinical } \\
\text { symptoms }\end{array}$ & $\begin{array}{c}\text { Neurological and } \\
\text { endocrinological } \\
\text { deficits }\end{array}$ & $\begin{array}{l}\text { Pre- } \\
\text { radiosurgical } \\
\text { treatment }\end{array}$ & $\begin{array}{c}\text { Tumor } \\
\text { volume } \\
\left(\mathrm{cm}^{3}\right)\end{array}$ \\
\hline 1 & $47 / F$ & breast & adeno & diplopia & $\begin{array}{l}\text { CN III paresis, } \\
\text { panhypo }\end{array}$ & craniotomy & 5.5 \\
\hline 2 & $67 / F$ & breast & adeno & ptosis & CN III paresis & & 6.9 \\
\hline 3 & $65 / F$ & lung & adeno & DI & DI & & 3.1 \\
\hline 4 & $78 / \mathrm{F}$ & lung & small cell & $\begin{array}{c}\text { consciousness } \\
\text { disturbance }\end{array}$ & panhypo & & 1.9 \\
\hline 5 & $74 / \mathrm{M}$ & lung & small cell & no symptoms & no deficits & WBRT (30 Gy) & 0.2 \\
\hline 6 & $43 / \mathrm{F}$ & lung & large cell & DI & DI & GKS & 0.9 \\
\hline 7 & $73 / \mathrm{M}$ & lung & squamous cell & $\begin{array}{l}\text { visual } \\
\text { disturbance }\end{array}$ & $\begin{array}{l}\mathrm{CN} \text { II-IV and VI } \\
\text { pareses }\end{array}$ & & 9.6 \\
\hline
\end{tabular}

CN: cranial nerve, DI: diabetes insipidus, panhypo: panhypopituitarism, WBRT: whole brain radiation therapy.

Table 2 Treatment data and outcomes in seven patients with pituitary metastases treated by gamma knife radiosurgery (GKS)

\begin{tabular}{|c|c|c|c|c|c|c|}
\hline $\begin{array}{l}\text { Case } \\
\text { No. }\end{array}$ & $\begin{array}{l}\text { Tumor } \\
\text { marginal } \\
\text { dose (Gy) }\end{array}$ & $\begin{array}{l}\text { Maximum } \\
\text { radiation dose } \\
\text { to optic } \\
\text { apparatus (Gy) }\end{array}$ & $\begin{array}{l}\text { Clinical outcome } \\
\text { after GKS }\end{array}$ & $\begin{array}{l}\text { Tumor size } \\
\text { after GKS }\end{array}$ & $\begin{array}{l}\text { Survival } \\
\text { period } \\
\text { after GKS } \\
\text { (months) }\end{array}$ & Outcome \\
\hline 1 & 13 & 10 & diplopia improved & decreased (PR) & $42^{*}$ & died of systemic disease \\
\hline 2 & 14 & 9.5 & ptosis improved & decreased (NC) & 10 & died of systemic disease \\
\hline 3 & 14 & 8 & DI improved & decreased (NC) & 12 & died of systemic disease \\
\hline 4 & 12 & 10 & unchanged & decreased (NC) & 3 & died of systemic disease \\
\hline 5 & 10 & 10 & - & - & 0.3 & $\begin{array}{l}\text { died of unknown causes } \\
10 \text { days after GKS }\end{array}$ \\
\hline 6 & 10 & 9 & DI improved & decreased (NC) & 10 & $\begin{array}{l}\text { alive, re-GKS for other } \\
\text { intracranial lesions }\end{array}$ \\
\hline 7 & 10 & 10 & diplopia improved & unchanged & 3 & died of systemic disease \\
\hline
\end{tabular}

${ }^{*}$ Tumor regrowth 18 months after GKS and surgery. NC: no change, PR: partial response.
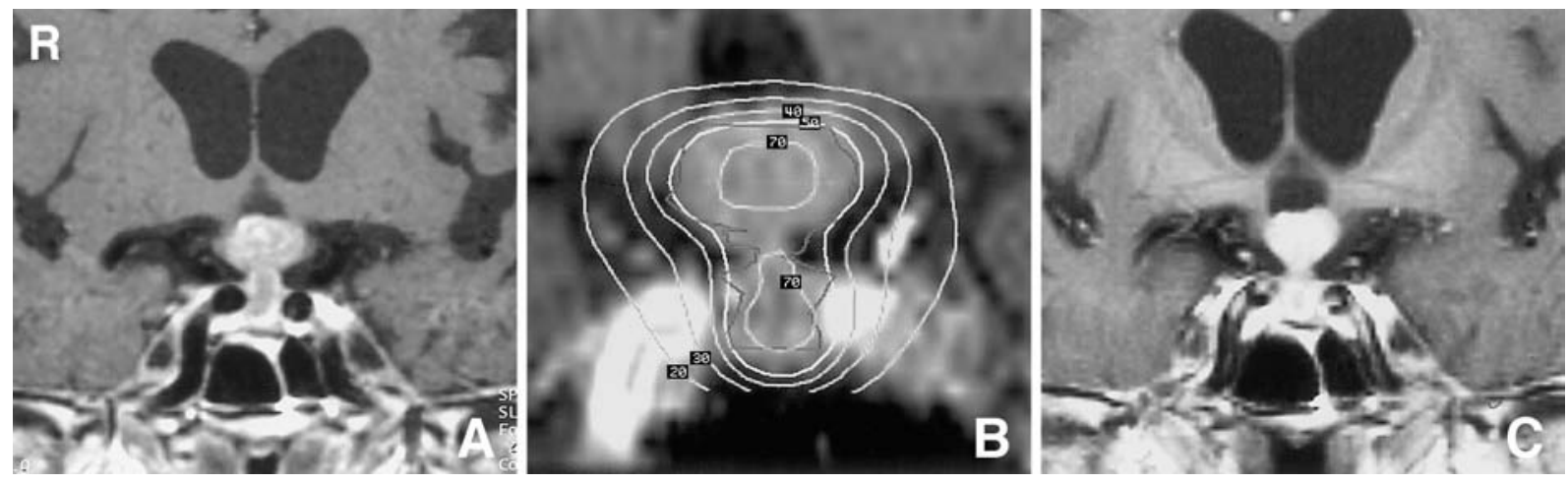

Fig. 1 Case 4. Coronal $\mathrm{T}_{1}$-weighted magnetic resonance images with gadolinium showing a pituitary metastasis as an intrasellar and suprasellar mass (A), treatment dose planning showing that the tumor margin was covered by the $50 \%$ isodose line (12 Gy) (B), and 2 months after gamma knife radiosurgery showing the tumor size was slightly decreased (C). 


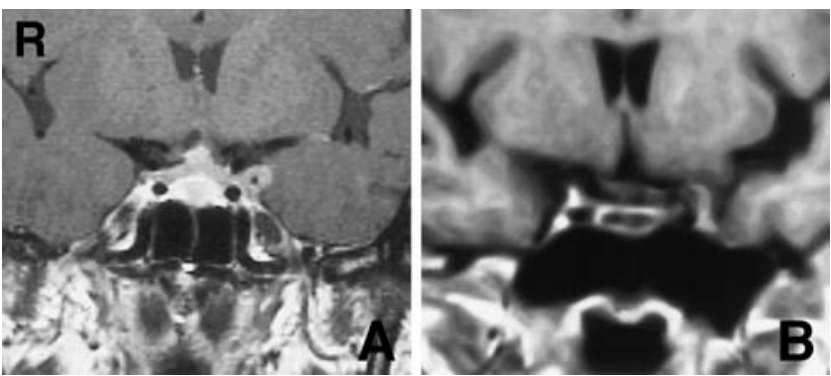

Fig. 2 Case 1. Coronal $\mathbf{T}_{1}$-weighted magnetic resonance images with gadolinium demonstrating an intrasellar tumor extending to the bilateral cavernous sinuses (A), and 10 months after radiosurgery demonstrating marked reduction in the tumor size (B).

tumor volume varied from 0.2 to $9.6 \mathrm{~cm}^{3}$ (mean $4.0 \mathrm{~cm}^{3}$ ). We used a relatively low marginal dose compared to the optimal dose for brain metastases, ${ }^{28)}$ because the tumors were in close proximity to the optic apparatus. The marginal dose for the tumors varied from 10 to $14 \mathrm{~Gy}$ (mean $11.9 \mathrm{~Gy}$ ) (Fig. 1, Table 2). We targeted the marginal dose slightly away from the optic apparatus, so that the planned irradiation to the optic apparatus was below $10 \mathrm{~Gy}$. The maximum radiation dose to the optic apparatus was between 8 and $10 \mathrm{~Gy}$ (mean $9.5 \mathrm{~Gy}$ ). Six patients were discharged on the following day after GKS except one patient with adrenal insufficiency.

Tumor regrowth was determined as any measurable tumor growth in any direction on MR imaging.

\section{Results}

One patient died of unknown causes 10 days after GKS, but the treatment procedure was no problem. The follow-up period for obtaining MR images after GKS was 2 to 18 months (mean 7.7 months) in the other six patients (Fig. 2). The tumor size decreased in five patients. Four patients had no change (tumor size decreased less than 50\%) and one patient had partial response (tumor size decreased $50 \%$ or more) (Fig. 2). The tumor regrow 18 months after GKS and was resected surgically in Case 1 . The tumor growth control rate was $83 \%$ during follow-up period.

The clinical status was improved in five patients (83\%) and unchanged in one patient after GKS (Table 2). The details regarding the clinically improved patients are as follows: oculomotor palsy improved in two patients, diabetes insipidus improved in two patients, and abducens nerve palsy improved in one patient. No patient developed new neurological deficits or new endocrinopathies due to radiation injuries caused by GKS. The survival time after GKS was 0.3 to 42 months (mean 11.5 months).

\section{Discussion}

Only $6.8 \%$ of pituitary metastasis cases found at autopsy were symptomatic, ${ }^{26)}$ and many metastatic lesions of the pituitary gland and sella turcica remain asymptomatic. ${ }^{13)}$ The clinical symptoms are different from those caused by pituitary adenomas. Lateral extension is common, so extraocular muscle pareses, in particular third cranial nerve involvement, are common, but decreased acuity and chiasmal compression are less common. ${ }^{4,11,15)}$ The metastases often involve the posterior lobe of the pituitary gland, so diabetes insipidus is more common compared to anterior pituitary dysfunction. ${ }^{7,12,13,15,17,26)}$ The incidences of clinical symptoms are as follows: diabetes insipidus $70 \%$, visual disturbances $20 \%$, ocular paresis $12.5 \%$, and anterior pituitary dysfunction $15 \% .{ }^{19)}$ Metastases to the anterior and posterior lobes occur with almost equal incidence with both lobes involved simultaneously in autopsy series. ${ }^{15)}$ The most common site of metastases is the anterior lobe from hypophysectomy specimens. ${ }^{6)}$ Anterior pituitary dysfunction may not be correctly identified, because the patients have terminal malignancies and present with symptoms such as malaise, weight loss, generalized pain, central nervous system involvement, or treatment-associated symptoms, so other diagnoses are established..$^{3,26)}$

The characteristic radiological findings of pituitary metastases do not include sella enlargement or bone erosion, which are important in the differential diagnosis, since pituitary adenomas commonly produce bone changes early in their course. ${ }^{23)}$ Enlargement of the floor of the sella is very rare with pituitary metastases. ${ }^{13)}$ Pituitary metastases appear as isointense on $\mathrm{T}_{1}$-weighted and $\mathrm{T}_{2}$-weighted $\mathrm{MR}$ images, with homogeneous or heterogeneous enhancement by gadolinium. In contrast, pituitary adenoma is isointense on $\mathrm{T}_{1}$-weighted MR images, slightly hyperintense on $\mathrm{T}_{2}$-weighted $\mathrm{MR}$ images, with homogeneous enhancement by gadolinium, so the intensity on $\mathrm{T}_{2}$-weighted images is critical. ${ }^{10,18,23)}$ Pituitary metastases tend to invade the cavernous sinus. Pituitary adenomas may also invade the surrounding structures, ${ }^{18)}$ but the radiological diagnosis is less pathognomonic. ${ }^{2,20,27)}$ However, pituitary metastases can be distinguished from pituitary adenomas based on radiological findings in patients with suspected pituitary masses and other metastases. ${ }^{23)}$ 
Pituitary metastases may be treated by transsphenoidal decompression and/or radiation therapy. The surgical indications are a symptomatic mass lesion and an uncertain diagnosis. ${ }^{1,20)}$ Nonetheless, surgery is more difficult compared to primary pituitary adenomas because blood loss is greater, and the lesions may be attached to the surrounding structures or show considerable invasiveness. ${ }^{10,21)}$ In addition, the choice between whole head and local radiation is difficult. ${ }^{11)}$ Local radiation therapy is recommended, ${ }^{17)}$ but given the possibility of subarachnoid spreading and meningeal carcinomatosis, whole brain radiation therapy may be better. ${ }^{10)}$

Radiosurgery may be considered less invasive than conventional radiation therapy from the standpoint of radiation effects on the surrounding structures. Also, radiosurgery is a one-day treatment and the treatment schedule is less invasive for the patients with brain metastases. Radiosurgery is useful for the treatment of brain metastases, ${ }^{14,25,28)}$ as well as skull base invasion. ${ }^{9)}$ Only one patient has been treated by GKS with pituitary metastasis resulting in rapid decrease of tumor size. ${ }^{8)}$ The limiting factor for radiosurgery of the pituitary lesion is the radiation dose to the optic apparatus. The tolerable dose for the optic nerves is 8 to $10 \mathrm{~Gy},{ }^{16)}$ so we used relatively low marginal doses compared to the doses for brain metastases (mean tumor marginal dose $11.9 \mathrm{~Gy}$ ). In addition, we set the marginal dose slightly away from the optic apparatus, so that the planned irradiation to the optic apparatus was below $10 \mathrm{~Gy}$ (mean 9.5 Gy). Radiosurgery is not indicated if the tumors infiltrate the optic nerves. However, most pituitary metastases do not affect the optic apparatus, ${ }^{4)}$ so many cases can be treated by radiosurgery.

Endocrinological dysfunction is one complication that occurred after conventional radiation therapy and radiosurgery. Endocrinological dysfunction after radiosurgery was found in $0 \%$ to $41 \%$ of cases of pituitary adenoma. ${ }^{5,24)}$ The difference in endocrinological dysfunction after radiosurgery depended on the follow-up period, the evaluation methods, and the radiosurgical dose, as well as the use of high doses.5) Pituitary function must be evaluated in patients with pituitary metastases. However, deterioration of endocrinological function will not cause clinical deterioration in many patients with pituitary metastases in the short term.

The mean survival time was 11.5 months in our series, but the prognosis is difficult to assess, because of the small number of patients. The prognosis for metastatic brain tumors depends on the control of systemic disease. ${ }^{28)}$ However, the largest clinical series of pituitary metastases (36 patients) indicates that the mean survival time is about 6 months, and patients with local tumor growth control had statistically longer survival times. ${ }^{20}$

GKS is effective and useful for the primary treatment of pituitary metastases with limited survival and lower invasiveness compared to conventional radiation therapy.

\section{References}

1) Branch CL Jr, Laws ER Jr: Metastatic tumors of the sella turcica masquerading as primary pituitary tumors. J Clin Endocrinol Metab 65: 469-474, 1987

2) Buonaguidi R, Ferdeghini M, Faggionato F, Tusini G: Intrasellar metastasis mimicking a pituitary adenoma. Surg Neurol 20: 373-378, 1983

3) Bynke O, Ottosson AM: Is metastatic breast carcinoma in the pituitary a concealed manifestation? Lancet 2: 1336-1337, 1982

4) Cox EV III: Chiasmal compression from metastatic cancer to the pituitary gland. Surg Neurol 11: 49-50, 1979

5) Feigl GC, Bonelli CM, Berghold A, Mokry M: Effects of gamma knife radiosurgery of pituitary adenomas on pituitary function. J Neurosurg 97 (5 Suppl): 415-421, 2002

6) Gurling KJ, Scott GBD, Baron DN: Metastases in pituitary tissue removed at hypophysectomy in women with mammary carcinoma. Br J Cancer 11: 519-523, 1957

7) Houck WA, Olson KB, Horton J: Clinical features of tumor metastases to the pituitary. Cancer 26: 656-659, 1970

8) Huang MC, Lee LS, Ho DMT, Cheng H, Chung WY, Huang CI, Hsiano CY, Pan DHC: A metastatic pituitary carcinoid tumor successfully treated with gamma knife radiosurgery. Zhonghua Yi Xue Za Zhi (Taipei) 64: 414-418, 2001

9) Iwai Y, Yamanaka K: Gamma knife radiosurgery for skull base metastasis and invasion. Stereotact Funct Neurosurg 72 (Suppl 1): 81-87, 1999

10) Juneau P, Schoene WC, Black P: Malignant tumors in the pituitary gland. Arch Neurol 49: 555-558, 1992

11) Kattah JC, Silgals RM, Manz H, Toro JG, Dritscilo A, Smith FP: Presentation and management of parasellar and suprasellar metastatic mass lesions. J Neurol Neurosurg Psychiatry 48: 44-49, 1985

12) Kimmel DW, O’Neill BP: Systemic cancer presenting as diabetes insipidus: Clinical and radiological features of 11 patients with a review of metastaticinduced diabetes insipidus. Cancer 52: 2355-2358, 1983

13) Kistler M, Pribram HW: Metastatic disease of the sella turcica. AJR Am J Roentgenol 123: 13-21, 1975

14) Kondziolka D, Patel A, Lunsford LD, Kassam A, Flickinger JC: Stereotactic radiosurgery plus whole brain radiotherapy versus radiotherapy alone for patients with multiple metastases. Int J Radiat Oncol Biol Phys 45: 427-434, 1999 
15) Kovacs K: Metastatic cancer of the pituitary gland. Oncology 27: 533-542, 1973

16) Leber KA, Berglöff J, Pendl G: Dose-response tolerance of the visual pathways and cranial nerves of the cavernous sinus to stereotactic radiosurgery. J Neurosurg 88: 43-50, 1998

17) Max MB, Deck MDF, Rottenberg DA: Pituitary metastasis: incidence in cancer patients and clinical differentiation from pituitary adenoma. Neurology 31: 998-1002, 1981

18) Mayr NA, Yuh WTC, Muhonen MG, Koci TM, Tali ET, Nguyen HD, Bergman RA, Jinkins JR: Pituitary metastases: MR findings. J Comput Assist Tomogr 17: 432-437, 1993

19) McCormik PC, Post KD, Kandji AD, Hays AP: Metastatic carcinoma to the pituitary gland. $\mathrm{Br} J$ Neurosurg 3: 71-80, 1989

20) Morita A, Meyer FB, Laws ER Jr: Symptomatic pituitary metastases. J Neurosurg 89: 69-73, 1998

21) Nelson PB, Robinson AG, Martinez AJ: Metastatic tumor of the pituitary gland. Neurosurgery 21: 941-943, 1987

22) Roessmann U, Kaufman B, Friede RL: Metastatic lesions in the sella turcica and pituitary gland. Cancer 25: 478-480, 1970

23) Schubinger O, Haller D: Metastases to the pituitaryhypothalamic axis. Neuroradiology 34: 131-134, 1992

24) Sheehan JP, Kondziolka D, Flickinger J, Lunsford LD: Radiosurgery for residual or recurrent nonfunction- ing pituitary adenoma. J Neurosurg 97 (5 Suppl): 408-414, 2002

25) Sneed PK, Suh JH, Goetsch SJ, Sanghavi SN, Chappell R, Buatti JM, Regine WF, Weltman E, King VJ, Breneman JC, Sperduto PW, Mehta MP: A multiinstitute review of radiosurgery alone vs radiosurgery with whole brain radiotherapy as the initial management of brain metastases. Int J Radiat Oncol Biol Phys 53: 519-526, 2002

26) Teears RJ, Silverman EM: Clinicopathologic review of 88 cases of carcinoma metastatic to the pituitary gland. Cancer 36: 216-220, 1975

27) Uzal MC, Kocak Z, Doganay L, Tokatli F, Caloglu M, Kilincer C: Pituitary metastasis mimicking a macroadenoma from carcinoma of the larynx: a case report. Tumori 87: 451-454, 2001

28) Yamanaka K: Prognostic factors for brain metastasis from lung cancer after gamma knife radiosurgery. Osaka City Med J 45: 45-59, 1999

Address reprint requests to: Y. Iwai, M.D., Department of Neurosurgery, Osaka City General Hospital, 2-13-22 Miyakojima-hondohri, Miyakojima-ku, Osaka 534-0021, Japan.

e-mail: y-iwai@rc5.so-net.ne.jp

Commentary on this paper appears on the next page. 


\section{Commentary}

The authors report a series of seven patients with pituitary metastases from primary lung and breast cancer treated with gamma knife radiosurgery. This is a rather large series of a rare entity of sellar lesions in which the majority of the cases are approached by many pituitary experts via a transsphenoidal route, especially for diagnostic reasons if the primary disease is unknown. Complete removal of these tumors is seldom achieved and surgery is more difficult than in pituitary adenomas. However, debulking of the tumor can also improve conditions for radiosurgery and dosimetry. The dose coverage in this series was 10 to $14 \mathrm{~Gy}$ to the tumor margin. The relatively low dose was chosen because of the proximity to the optic apparatus. For this reason the authors seemed also to accept compromises in the conformity index of their dose prescriptions, although they did not provide actual numbers. The tumor control rate was $83 \%$ in follow ups and $83 \%$ in clinical symptoms improved. This is an interesting report on a rare entity that adds to the body of literature of radiosurgery. It would be interesting if the authors could have also included ophthalmological data of the patients since the exposure of the chiasm is specified as 8 to $10 \mathrm{~Gy}$ (mean $9.5 \mathrm{~Gy}$ ). This dose slightly exceeds the tolerance of the chiasm which should not exceed $8 \mathrm{~Gy}$ in our institution, which uses the NOVALIS LINAC bases system for radiosurgery. However, in their series of palliative patients this seems to be acceptable. This paper states clearly that radiosurgery is an expedient adjuvant treatment option for pituitary metastases in selected cases.

Rudolf FAHLBUSCH, M.D. and Oliver GANSLANDT, M.D. Department of Neurosurgery and Radiosurgery Unit University Erlangen Erlangen, Germany

This paper reports an excellent series of cancers metastatic to the pituitary gland. It is evident that these lesions present in a fairly characteristic pattern and can often be diagnosed presumptively. This series clearly demonstrates the practical utility of utilizing gamma knife radiosurgery for the management of these lesions. Clearly most of them are highly responsive to gamma knife radiosurgery, and the outcome with regard to remission of the pituitary lesion and longevity is very similar to what is seen with open transsphenoidal removal, and in many cases may be safer for the patient. This is an important part of the combined modality therapy of the treatment of such lesions, and should encourage others to consider gamma knife radiosurgery as a means to achieve improved outcome and quality of life for our patients with pituitary metastases.

Edward R. LAws, Jr., M.D., F.A.C.S. Department of Neurosurgery University of Virginia Charlottesville, Virginia, U.S.A.

This is an important contribution and review of the literature on the difficult subject of pituitary metastasis. The authors analyze 7 patients submitted to gamma-knife radiosurgery treatment, among whom only one had a previous surgical approach, basing their diagnosis on magnetic resonance imaging. The final diagnoses were inferred from lung cancer in five and breast cancer in two patients; most of them dying from systemic disease after a mean survival of 11.5 months; tumor size decreasing in 5 patients. It is important to notice that the authors planned their irradiation below $10 \mathrm{~Gy}$ due to the proximity of the optic chiasm, since a larger dose could cause damage to the optic pathways. However, we should remember that other sellar lesions like adenomas and carcinoma may masquerade or mimic metastatic lesions or viceversa, if not verified by a biopsy, which was not performed in the majority of the present cases, the authors relying only in radiological and clinical data.

Raul Marino, Jr., M.D. Department of Neurosurgery University of São Paulo Medical School Instituto Neurológico de São Paulo São Paulo, Brazil 